\title{
Long term survival in Indian childhood cirrhosis treated with $\mathrm{D}$-penicillamine
}

\author{
A R Bavdekar, S A Bhave, A M Pradhan, A N Pandit, M S Tanner
}

\begin{abstract}
Indian childhood cirrhosis (ICC) is an almost uniformly fatal disease whose outcome may be modified with penicillamine if given at a sufficiently early stage. Twenty nine children with ICC seen in Pune, India, in 1980-7, who had survived at least five years from onset of penicillamine treatment, were reviewed aged $6 \cdot 3$ to 13 years. They were assessed clinically, biochemically, histologically, and by duplex Doppler ultrasound examination. None had symptoms suggestive of liver disease. There were no toxic effects of penicillamine other than asymptomatic proteinuria. Hepatosplenomegaly reduced significantly and liver function tests returned to normal in all. In four children, significant hepatosplenomegaly was associated with an abnormal duplex Doppler hepatic vein flow pattern and micronodular cirrhosis on biopsy. Clinical findings, growth and development, and ultrasound examination were normal in the remainder. Review of serial liver biopsy specimens showed a sequence of recovery from ICC through inactive micronodular cirrhosis to virtually normal histological appearances. The four children who still have micronodular cirrhosis beyond four years from onset remain on penicillamine treatment. In the others penicillamine was stopped after 1-7 (mean 3.5) years without relapse, strong evidence that ICC is not due to an inborn error of copper metabolism.

(Arch Dis Child 1996; 74: 32-35)
\end{abstract}

Keywords: cirrhosis, copper, penicillamine.

Indian childhood cirrhosis (ICC) used to be common among rural, middle income Indian children aged 1-4 years. ${ }^{1-4}$ Males predominated and familial incidence was high. It had a rapidly progressive course and, without treatment, almost all died within months. The consistent demonstration of greatly increased hepatic copper in ICC $^{5} 6$ led to therapeutic trials with the copper chelating agent D-penicillamine and short term survivors are now being reported from many centres. ${ }^{7-10}$ This raises a number of questions. Does survival imply that cirrhosis has been reversed? Do survivors have normal growth, development, and liver function? Are there any long term effects of the drug? The objective of this study was to address these questions by assessing children with ICC who have survived for at least five years from onset of penicillamine treatment.
Patients and methods

A prospective study of chronic liver disease in children began in Pune in $1980,{ }^{4}$ chronic liver disease being defined as clinical or histological evidence of liver disease for more than four weeks. From 1980-93, 797 children with liver disorders were seen of whom 298 were diagnosed as having ICC on the histological criteria of (i) hepatocyte necrosis, ballooning, hyaline inclusions, and granular orcein staining and (ii) pericellular intralobular fibrosis. ${ }^{4}$ Children with ICC entered two controlled trials of penicillamine. The diagnostic criteria, patient allocation, schedules of treatment, and outcome have previously been described and are summarised here. Both were randomised controlled trials, using penicillamine in a dose of $20 \mathrm{mg} / \mathrm{kg} /$ day. The first trial included 30 cases, randomly allocated to treatment and placebo groups. The second included only cases who had not progressed to the stage of developing ascites or jaundice and had three arms: penicillamine, penicillamine with prednisolone $2 \mathrm{mg} / \mathrm{kg} /$ day for four weeks and thereafter $5 \mathrm{mg} /$ day, and placebo. ${ }^{7}$ Because no statistically significant difference was apparent in the outcome of children given or not given steroids they are considered together in this report. Children in the trial were reviewed every 1-3 months in the first year and later every 6-12 months. Defaulters were followed up with a home visit by a medical social worker. Percutaneous liver biopsies were scheduled at three, six, and 12 months from onset of treatment and subsequently as indicated. It was planned to continue penicillamine until recovery or death occurred. 'Recovery' seemed an unlikely outcome at the beginning of the study and was therefore not rigidly prospectively defined.

In this study of children with ICC who were treated before December 1987 and who have survived at least five years from onset of penicillamine treatment, the following assessments were made:

(1) Parental interview and clinical examination. Because no accurate weight centile charts exist for children in rural Maharashtra, SD scores for weight using National Center for Health Statistics (NCHS) data were computed at presentation and review. Approximate NCHS SD scores for the 25th and 50th centiles on charts produced by the Indian Council of Medical Research are -2.4 and -1.5 .

(2) Haemogram, liver function tests, prothrombin time, and platelet count.

(3) Abdominal ultrasonography using an AIOKA SSD 650 ultrasound scanner. Duplex Doppler flow measurements of the splenic, 


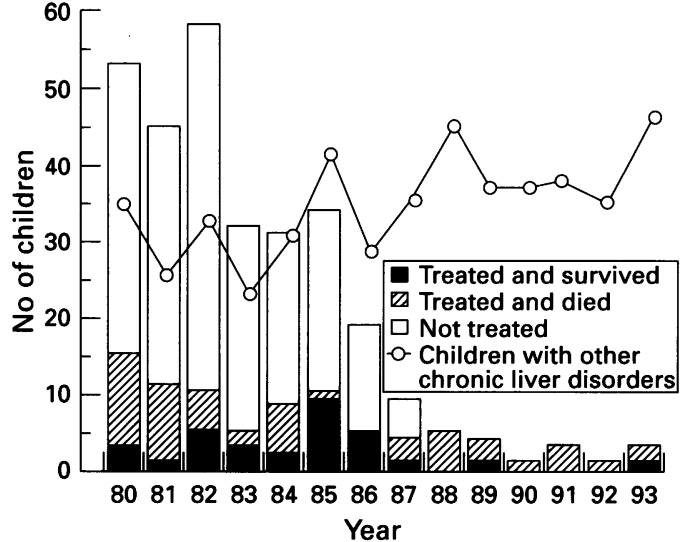

Numbers of children with ICC who were treated with penicillamine and survived, were treated with penicillamine and died, or who were not treated with penicillamine are shown in columns, and children with other chronic liver disorders, for the period 1980-93.

portal, hepatic veins, and collaterals. The hepatic veins were insonated about $2 \mathrm{~cm}$ proximal to their junction with the inferior vena cava. A triphasic flow pattern of the hepatic veins was considered normal, while monophasic or biphasic wave forms were considered abnormal and suggestive of parenchymal liver disease. ${ }^{11} 12$

(4) Histology - a percutaneous liver biopsy was planned after informed consent if there was significant hepatosplenomegaly, raised plasma transaminases, or growth failure. Previous liver biopsy specimens were reviewed and scored as previously described. ${ }^{13}$

A comparison with respect to features present at start of treatment was made between penicillamine treated children who survived and those who died.

Statistical analyses was by $\chi^{2}$ or paired $t$ test as appropriate, using Bonferroni's correction for multiple comparisons.

Table 1 Comparison of penicillamine treated children with ICC who survived or who died with respect to features at presentation

(A) Discontinuous variables. Domicile is given as urban/Pune rural district/outwith Pune district. Significance values $(p)$ are derived from the $\chi^{2}$ distribution, and corrected by the Bonferroni method (kp)

\begin{tabular}{|c|c|c|c|c|c|}
\hline & $\begin{array}{l}\text { Alive } \\
(n=29)\end{array}$ & $\begin{array}{l}\text { Dead } \\
(n=39)\end{array}$ & $x^{2}$ & $p$ Value & $k p$ \\
\hline $\begin{array}{l}\text { Ascites } \\
\text { Jaundice } \\
\text { Boys } \\
\text { Domicile }\end{array}$ & $\begin{array}{c}4 \\
1 \\
24 \\
2 / 1 / 26\end{array}$ & $\begin{array}{l}10 \\
16 \\
31 \\
4 / 8 / 27\end{array}$ & $\begin{array}{r}1.43 \\
12.53 \\
0.12 \\
4 \cdot 76\end{array}$ & $\begin{array}{l}\text { NS } \\
<0.0001 \\
\text { NS } \\
\text { NS }\end{array}$ & 0.0004 \\
\hline
\end{tabular}

(B) Continuous variables. The histology score of liver biopsies is described in Pradhan et al. ${ }^{13}$ The $95 \%$ confidence interval (CI) is shown for the difference between means of groups, and significance ( $p$ and $\mathrm{kp}$ ) values calculated by unpaired $t$ test. No differences were found between groups for spleen size, haemoglobin, white cell count, platelets, plasma albumin, or prothrombin time

\begin{tabular}{lccccc} 
& $\begin{array}{c}\text { Alive } \\
(n=29)\end{array}$ & $\begin{array}{c}\text { Dead } \\
(n=39)\end{array}$ & $C I$ & $p$ Value & $k p$ \\
\hline Bilirubin $(\mu \mathrm{mol} / \mathrm{l})$ & & & & & \\
$\quad$ Total & 18 & 37 & 11 to 27 & 0.0001 & 0.001 \\
$\quad$ Conjugated & 7 & 16 & 3 to 14 & 0.0022 & 0.024 \\
ALT (U/ $/)$ & 85 & 123 & 13 to 64 & 0.004 & 0.044 \\
Hepatic copper $(\mu \mathrm{g} / \mathrm{g}$ dry weight) & 1139 & 1723 & 229 to 939 & 0.0018 & 0.02 \\
Histology score & 10 & 17 & 3.9 to 9.6 & 0.0001 & 0.001
\end{tabular}

(C) Relevant variables in cases with bilirubin $<17 \mu \mathrm{mol} / 1$ at presentation

\begin{tabular}{lcccll} 
& $\begin{array}{l}\text { Alive } \\
(n=19)\end{array}$ & $\begin{array}{c}\text { Dead } \\
(n=8)\end{array}$ & \multicolumn{1}{c}{$C I$} & $p$ Value & $k p$ \\
\hline ALT (U/) & 80 & 72 & -26 to 43 & NS & \\
Hepatic copper & 1262 & 1785 & -237 to 1283 & NS & \\
Histology & 10.7 & 16.2 & 1.7 to 9.3 & 0.0087 & 0.01 \\
\hline
\end{tabular}

\section{Results}

Five hundred and thirty seven children with chronic liver disease were seen between 1980 and 1987, of whom 281 had ICC (figure). Of these, 19 came from the conurbation of Pune, 90 from the largely rural Pune District, and 172 from outwith Pune District. The population of Pune conurbation and district was 4170489 in 1981. The incidence of ICC declined after 1983 in association with an education programme aimed at preventing the use of brass vessels for infant feeds. ${ }^{14} 15$ This trend continued with only 17 cases of ICC being seen from 1988 to 1993 , of whom 14 were referred from outwith Pune District.

In the first two years (1980-1) 26 patients received penicillamine. These included many advanced cases, and only four (15\%) survived more than five years. In 1982, a trial of penicillamine in 'preterminal' ICC started, including only those patients who had not developed ascites or jaundice at the time of presentation. Between 1982 and 1987, 42 patients with ICC received penicillamine, with or without prednisolone. Twenty five $(60 \%)$ of these have survived at least five years. The 17 ICC cases presenting from 1988-93 were clinically advanced. Although selection criteria for penicillamine treatment were relaxed and most received treatment, only two currently survive.

Thirty nine of 68 cases treated before 1987 died, 26 within three months of diagnosis and only four after one year of treatment. The late deaths occurred at home, and none had postmortem examinations. The cause of death was recorded by the local health worker as sepsis in one, acute febrile illness in one, and hepatocellular failure in the rest.

Retrospective review of features present at the start of treatment in the 68 cases showed that of 17 children with jaundice, only one survived (table 1). Ascites alone proved not to be discriminant. The laboratory features which distinguished survivors were total bilirubin, conjugated bilirubin, alanine aminotransferase (ALT), hepatic copper concentration, and liver biopsy histology score (table 1B). When only the 27 cases in whom the total bilirubin concentration was $<17 \mu \mathrm{mol} / 1$ were considered, hepatic copper and ALT became nondiscriminatory, only the histology score remaining predictive (table $1 \mathrm{C}$ ).

Further analysis is restricted to the 29 treated ICC patients who have survived for more than five years. In this group, treatment was started at age 1.5 (range $0.5-4$ ) years. They were reviewed at $8 \cdot 8$ (range $6 \cdot 3-13$ ) years, 5-12 years since diagnosis. On systematic inquiry, none had complaints suggestive of liver disease or portal hypertension. Vague complaints of 'not doing well' were reported by two mothers, poor appetite by four, and unusual frequency of infections by two.

At presentation, all had the enlarged hard liver characteristic of ICC, the liver being $5 \cdot 8$ (range 2-9) $\mathrm{cm}$ below the costal margin. Nineteen had splenomegaly, the spleen being $1-4 \mathrm{~cm}$ below the costal margin. On review, liver size had reduced significantly in all $(p<0.05)$. Four demonstrated firm 
hepatomegaly of $1-4 \mathrm{~cm}$ in the right midclavicular line. In 15 others only the left lobe was palpable in the epigastric region but was soft and less than $1 \mathrm{~cm}$ below the costal margin. This was regarded as normal. Splenomegaly was present in six, including the four with hepatomegaly. None had ascites or jaundice. The blood count, ALT, and prothrombin time were within normal limits in all. Weight SD scores rose from -2.9 (SD 0.9 ) at presentation to $-1.9(\mathrm{SD} 0.7)$ at review $(\mathrm{p}=0.003)$. Academic performance, as judged by school reports, was poor in two but within expected standards in the others. None has yet shown signs of puberty.

The mean duration of penicillamine treatment was 3.5 (range 1-7 years). The four patients with hepatosplenomegaly are still on treatment, the remainder having discontinued treatment 5.3 (SD 3.2 , range $2-10.5$ ) years ago. There were no major side effects of penicillamine. Mild proteinuria occurred in five patients but did not increase on continuing treatment.

Ultrasound examination was performed in 21 patients. None showed features of portal hypertension. Hepatosplenomegaly was confirmed in four, and in these duplex Doppler examination revealed a wave pattern consistent with reduced hepatic compliance as in hepatic fibrosis/cirrhosis. Doppler studies were normal in all the other children.

The four children with hepatosplenomegaly underwent liver biopsy, which in each case showed inactive micronodular cirrhosis. We reviewed the most recent biopsy specimens in the other 25 cases. Ten were essentially normal, showing minimal portal fibrosis. In 12, the last biopsy, performed less than three years from diagnosis, the specimen showed inactive micronodular cirrhosis and has not been repeated because the child is well. In three children, the only biopsies performed were in the first year and the specimens showed continuing features of ICC (table 2).

\section{Discussion}

The short term therapeutic benefit of penicillamine in preterminal ICC has now been shown to be associated with long term survival. Whereas untreated preterminal ICC has a mortality of $93 \%,{ }^{7} 59 \cdot 6 \%$ preterminal cases treated in the period 1982-7 survive. Twenty three of 29 survivors have no clinical, ultrasound, or biochemical abnormality and have been off penicillamine for $5 \cdot 3$ (range $2-10 \cdot 5$ ) years.

The rapid clinical resolution seen in survivors made it difficult to persuade some parents to continue penicillamine treatment

Table 2 Histological appearances of last biopsy specimen from 29 penicillamine treated cases of ICC

\begin{tabular}{lllll}
\hline & \multicolumn{4}{c}{ Time since diagnosis (years) } \\
\cline { 2 - 5 } Histology & $<1$ & $1-3$ & $3-5$ & $>5$ \\
\hline Thick pseudolobules \pm hepatocytic features of ICC & 3 & - & $\overline{1}$ & - \\
Inactive micronodular cirrhosis & 4 & 8 & 3 & - \\
Normal biopsy specimen or with few fibrous septa only & - & 7 & 3 & \\
\hline
\end{tabular}

regularly, so the reported duration of treatment may be an overestimate. The optimum duration of treatment in ICC is unknown. There were surprisingly no toxic effects of penicillamine in spite of continuous long term use over 1-7 years. As experience grew in the present series, penicillamine was discontinued after two years if the child was clinically and biochemically normal. The absence of relapse after discontinuation of penicillamine is in contrast to the experience in Wilson's disease, suggesting that the liver cell injury and copper accumulation characteristic of ICC are acquired phenomena of infancy rather than an inborn error of metabolism. Similar conclusions were reached in a recent study of copper induced metallothionein synthesis in ICC. ${ }^{16}$

Clinical recovery also made it difficult to insist upon review liver biopsies. The histological sequence seen in recovering ICC, from florid disease through inactive micronodular cirrhosis to residual fibrotic changes to normal, has previously been reported in children who had two or more biopsies. ${ }^{1013}$ In 10 children in this series, follow up biopsy specimens demonstrated return to normal liver histology. Fifteen refused further biopsies because of apparent clinical recovery. Review of their last biopsy specimen, performed less than three years from diagnosis, showed inactive micronodular cirrhosis. In such children, the simple noninvasive technique of duplex Doppler was especially useful to screen for liver dysfunction and/or portal hypertension. Continued follow up throughout childhood is desirable to detect late sequelae, but on present evidence they are cured.

However, four children have continuing hepatosplenomegaly and histological micronodular cirrhosis in biopsies taken more than five (in three cases) and three (in one case) years after diagnosis. These cases pose a management dilemma. We have elected to continue penicillamine, as the course of this fibrotic sequel to the earlier hepatocytic injury is currently unknown.

Although these results are encouraging, the overall prognosis for ICC remains very poor. Only 29/281 patients survive. Earlier presentation would change these results significantly. However, ICC is preventable and its decline would make these data merely of historical interest were it not for the occurrence of a fatal ICC like illness in other parts of the world. ${ }^{17-21}$ These sporadic cases of apparent infantile copper toxicosis have had a stereotyped history. They have occurred in rural families with a private well, the well water being of low $\mathrm{pH}$ and acquiring high copper concentration from plumbing. Awareness of this entity would allow earlier diagnosis and treatment with penicillamine.

Given the overall poor prognosis in ICC, such cases of infantile copper toxicosis should start penicillamine immediately. In the present ICC series, a normal plasma bilirubin concentration and a histology score of less than 14 were associated with survival in $86 \%$ of cases, while a raised bilirubin and histology score greater than 14 with death in $90.4 \%$. 
Notwithstanding possible differences between ICC and sporadic infantile toxicosis and effects of more intensive supportive care than could be offered in Pune, present evidence suggests that sporadic cases falling into the latter group require urgent liver transplantation.

We acknowledge support from the Wellcome Trust.

1 Sen BC. Enlargement of the liver in children. Transactions of the Calcutta Medical Society. Indian Medical Gazette of the Calcutta Medi 22: 338-43.

2 Nayak NC, Visalakshi S, Singh M, et al. Indian childhood cirrhosis. A reevaluation of its pathomorphologic features and their significance in the light of clinical data and natural history of the disease. Indian $\mathcal{F}$ Med Res 1972; 60: 246-59.

3 Tanner MS, Portmann B. Indian childhood cirrhosis. Arch Dis Child 1981; 56: 4-6.

4 Bhave S, Sidhaye D, Pradhan A, et al. Paediatric liver disease in India. Arch Dis Child 1982; 57: 922-8.

5 Tanner MS, Portmann B, Mowat AP, et al. Increased hepatic copper concentration in Indian childhood cirrhosis. Lancet 1979; i: 1203-5.

6 Popper H, Goldfisher S, Sternlieb I, Nayak NC, Madhavan TV. Cytoplasmic copper and its toxic effects. Studies in Indian childhood cirrhosis. Lancet 1979; i: 1205-8.

7 Tanner MS, Bhave SA, Pradhan AM, Pandit AN. Clinical trials of penicillamine in Indian childhood cirrhosis. trials of penicillamine in Indian

8 Tomar BS, Saxena S, Prakash P, et al. D-Penicillamine in treatment of ICC - a preliminary report. Indian $\mathcal{F}$ Pediatr 1983; 50: 613-8.

9 Kalra V. Dietary $\mathrm{Cu}$ and ICC. Indian Pediatr 1986; 23: 399-401. 10 Bhusnurmath SR, Walia BNS, Singh S, Parakash D,
Radotra BD, Nath R. Sequential histopathologic alterations in Indian childhood cirrhosis treated with D-penicillamine. Hum Pathol 1991; 22: 653-8.

11 Bolondi L, Bassi SL, Gaiani S, et al. Liver cirrhosis: changes of Doppler waveform of hepatic veins. Radiology 1991; 178: 513-6.

12 Longo JM, Eleno A. Duplex Doppler of the hepatic veins in patients with cirrhosis - pseudoportal pattern. Radiology 1989; 173: 361 .

13 Pradhan AM, Bhave SA, Joshi VV, Bavdekar AR, Pandit AN, Tanner MS. Reversal of cirrhosis after D-penicillamine therapy in preicteric Indian childhood cirrhosis. f Pediatr Gastroenterol Nutr 1995; 20: 28-35.

14 Bhave SA, Pandit AN, Tanner MS. Comparison of feeding history of children with Indian childhood cirrhosis and paired controls. F Pediatr Gastroenterol Nutr 1987; 6: p62-7.

15 Bhave SA, Pandit AN, Singh S, Walia BNS, Tanner MS The prevention of Indian childhood cirrhosis. Ann Trop Paediatr 1992; 12: 23-30.

16 Hahn SI, Tanner MS, Danks D, Gahl WA. Normal metallothionein synthesis in fibroblasts obtained from children with Indian childhood cirrhosis or copper associated childhood cirrhosis. Biochemical and Molecular Medicine 1995; 54: 142-5.

17 Muller-Hocker J, Weiss M, Meyer J, et al. Fatal copper storage disease of the liver in a German infant resembling Indian childhood cirrhosis. Virchows Arch A 1987; 411: 379-85.

18 Weiss M, Muller-Hocker J, Wiebecke B, Belohradsky BH. First description of 'Indian childhood cirrhosis' in a nonIndian infant in Europe. Acta Paediatr Scand 1989; 78: 152-6.

19 Muller-Hocker J, Meyer U, Wiebecke B, et al. Copper storage disease of the liver and chronic dietary copper intoxication in two further German infants mimicking Indian childhood cirrhosis. Pathol Res Pract 1988; 183: $39-45$

20 Schramel P, Muller-Hocker J, Meyer U, Weiss M, Eife R. Nutritional copper intoxication in three German infants with severe liver cell damage (features of Indian childhood cirrhosis). I Trace Elem Electrolytes Health Dis 1988; 2: 85-9.

21 Walker-Smith J, Blomfield J. Wilson's disease or chronic copper poisoning? Arch Dis Child 1973; 48: 476-9. 